\title{
El problemático carácter de lo étnico
}

\author{
Maya Lorena Pérez Ruiz ${ }^{1}$
}

Trabajo recepcionado: junio 2007

Trabajo aceptado: julio 2007

\begin{abstract}
RESUMEN
En este ensayo se discuten los problemas que existen para caracterizar la etnicidad y a los grupos étnicos, y como aportación, se propone una definición de lo étnico que enfatiza el papel de la dominación y de la construcción social del "otro" como elementos esenciales. Se considera como una forma de clasificación que se ejerce desde las sociedades y grupos dominantes para designar a los "otros"; y que sobre la base de las diferencias culturales, establece fronteras y justifica las relaciones de dominación que se ejercen sobre ellas. Así, lo étnico correspondería a un tipo específico de dominación que se sustenta y argumenta sobre la base de la diferencia cultural, y que se emplea para explicar y justificar relaciones asimétricas y de subordinación sobre grupos sociales considerados, desde el poder, como culturalmente diferentes.
\end{abstract}

PALABRAS CLAVE: etnicidad, étnico, construcción social, dominación.

\begin{abstract}
This essay discusses the problems exiting in characterizing ethnicity and ethnic groups, and as an input, proposing a definition of the ethnic, and emphasizing the role of domination and the social construction of the "other" as essential elements. It is considered as a form of classification that is exerted from societies and dominant groups to designate the "others"; and that based on cultural differences, sets boundaries and justifies the relations of domination that is exerted on them. Therefore, the ethnic would correspond to a specific type of domination that is sustained and argued on the basis of cultural difference, and used to explain and justify asymmetric and subordinated relations of social groups considered, from power, as culturally different.
\end{abstract}

KEY WORDS: ethnicity, ethnic, social construction, domination.

1 Doctora en Ciencias Antropológicas. UAM-I. México. 


\section{Las dificultades para caracterizar lo étnico}

En la actualidad el concepto de grupo étnico, y de la etnicidad como concepto asociado, es polisémico y su definición y caracterización está envuelta en fuertes polémicas en el ámbito internacional. Las diferentes escuelas de pensamiento lo han definido según sus ámbitos de interés y aplicación: se emplea para caracterizar a poblaciones originarias de América (etnia asociado a indígena), a inmigrantes de diversos orígenes que llegan a los países metropolitanos (etnia asociado a minoría); así como a unidades culturales o pueblos que, con una relación estrecha entre su identidad y su cultura, buscan ser reconocidos, o como naciones, o como estados (etnia asociado a nación). Por otra parte, las limitaciones de las definiciones extremas primordialistas - constructivistas así como la emergencia como actores de diversos suj etos étnicos, han influido en la necesidad de revisar el sentido de lo étnico, y las consecuentes definiciones de etnia, grupo étnico y etnicidad.

Aún en América Latina, en donde hay más similitudes en la definición de quienes conforman una etnia, puesto que comúnmente se aplica a los indígenas, varían las definiciones y los criterios para hacerlo. Lo común es que lo étnico, lo que le da carácter de grupo étnico a una población, se asocie con determinadas cualidades de origen, cultura, organización, territorio e identidad, asociadas con el carácter prehispánico de los grupos indígenas a los que se aplica; aunque también hay quienes consideran que lo étnico es una cualidad cultural que identificaría y cohesionaría a cualquier grupo social, por lo que todas las poblaciones unificadas por una cultura, una identidad y una trayectoria serían etnias (habría una etnia mestiza, por ejemplo) (Díaz Polanco, 1995).

La mayor parte de las definiciones de grupo étnico, de etnia, son empleadas para caracterizar solo a ciertos grupos sociales, insisten más en los elementos culturales (origen, lengua, cultura y religión) que en los biológicos para establecer su carácter étnico, aunque pueden incluir criterios raciales y fenotípicos como sucede cuando se crean las denominaciones étnicas de "afros", "asiáticos", "hispanos", "sudacas", etc.

Para el caso de los indígenas, es común que su carácter étnico se establezca a partir de la presencia de ciertos rasgos emblemáticos: hablar una lengua de bases prehispánicas (aunque con elementos de la sociedad colonial y de la contemporánea) y diferente a la de la sociedad nacional; tener un sistema ritual y simbólico propio (aunque pueda estar influido por la religión católica); mantener ciertas formas de organización social propias y diferentes a las predominantes en el Estado nacional del que forma parte; sustentar su identidad en un origen común mítico y de sangre (primordialismo); y poseer un territorio -real o simbólico-propio. Algunos autores agregan o redefinen otros elementos más: tener una historicidad anterior a la de los Estado-Nación; poseer una lógica y una historicidad diferentes a la de las clases sociales; estar bajo el dominio de los Estados-nación modernos en una condición asimétrica y desigual; mantener un sentido de identidad y pertenencia propio; o haber sido desterritorializados, ya sea por procesos coloniales, por imposición de los Estados nacionales, o por procesos migratorios.

El problema de emplear para definir a un grupo étnico rasgos o elementos culturales, de primordialidad, de ancestralidad y aun organizacionales 0 de ser anteriores a los estados nacionales, naturaliza y sustancializa el carácter de lo étnico y su definición y aplicación requiere verificar la presencia o ausencia de ciertos elementos culturales y organizativos, e incluso de constatar la existencia (uso y utilidad) de proyectos culturales y/o políticos para conservar esos rasgos. Por otra parte, la diversidad de grupos, culturas e identidades a los que se aplica la denominación de ser étnicos, deriva en otros problemas: o no hay coherencia, y se crean definiciones y caraterizaciones sean las poblaciones a las que se trata o se construye 
UNIVERSIDAD CATÓLICA DE TEMUCO

un "imaginario" de lo que es o debe ser un grupo étnico, omitiendo las diferencias que existen entre las poblaciones y grupos a los que se aplica, creando estereotipos.

En cuanto a emplear el criterio territorial, tanto en la versión de poseer un territorio, 0 en la de haber sido desterritorializados por los procesos coloniales, nacionales o por la migración, estriba en que, por una parte, muchas de las poblaciones actuales indígenas de América Latina han desarrollado importantes luchas por la recuperación de sus territorios, y ya los poseen en diversas modalidades y aún así siguen siendo caracterizadas como étnicas; mientras que, por otra parte, con la intensificación y ampliación de los movimientos migratorios (forzados 0 voluntarios) algunas de las poblaciones étnicas se han relocalizado, y reorganizado, en nuevos ámbitos, urbanos y transnacionales, y pueden mantener relaciones simbólicas o reales con su territorio de origen, pero sin que ello parezca ser la condición indispensable para que sean caracterizados como etnias. Por ejemplo, el carácter de "hispanos" que se le asigna a los que hablan español en Ios Estados Unidos, no tiene en ningún caso como condición que todos los así denominados tengan entre sí lazos organizativos e identitarios, ni tampoco que mantengan un lazo activo y simbólico con su territorio de origen. $Y$ algo similar sucede con los denominados "asiáticos" en Canadá.

Finalmente, recurrir para la identificación de una etnia a los emblemas culturales, a la cohesión identitaria, a los procesos de idealización del pasado para marcar continuidades y proyecciones al futuro, así como al mito del origen común y a la comunidad de sangre real o simbólica, tampoco parece ser adecuado, pues tales características no son exclusivas de las poblaciones Ilamadas étnicas. Por el contrario, son recursos simbólicos empleados también por otro tipo de unidades organizacionales para justificar su existencia. Como sucede, por ejemplo, con las naciones-estado; por lo que queda por resolver cuáles son las diferencias entre una etnia y una nación, y qué es, entonces, lo específico de lo étnico.

Además de lo anterior hay problemas adicionales cuando en países como Canadá se denominan étnicas no las poblaciones originarias, como sucede en América Latina, sino a los inmigrantes, sean estos latinoamericanos, africanos o asiáticos. De modo que cabe preguntarse ¿qué tienen en común una etnia altiplánica y una selvática de Ecuador, Bolivia, Perú o Brasil? ¿Qué tienen en común estos grupos de procedencia prehispánica del sur con las del norte de México, de Estados Unidos o de Canadá? ¿Y qué tienen en común estas poblaciones con los inmigrantes de África, Asia, India, Europa del Este y de China que Ilegan a Estados Unidos, Canadá y Europa? ¿Qué hace que todas esas poblaciones sean consideradas como étnicas?

La única forma de encontrar respuestas satisfactorias pareciera ser recuperar la historicidad de los conceptos asociados a lo étnico y analizar las diferentes propuestas de definición y empleo de tales conceptos para identificar problemas y recuperar aportaciones.

\section{¿De qué hablamos cuando se denomina a un grupo como étnico?}

Quizá la primera referencia sobre el tema venga de la Grecia antigua cuyos habitantes empleaban la palabra ethnikos para denominar a los pueblos que no habían adoptado el modelo político y social de la ciudad-Estado; es de advertirse que su uso estaba desprovisto de connotaciones raciales y se empleaba para nombrar y caracterizar al "otro", pagano o no griego; mientras que ethnos se refería a la gente de una nación o tribu.

Como concepto analítico, la etnia aparece en la lengua francesa a finales del siglo XIX; una época en la que dominaba el evolucionismo, y durante la cual Francia legitimaba la colonización gracias a su "misión civilizadora". Vale la pena recordar que es entonces cuando se designa a la etnología 
como la ciencia de las sociedades primitivas, en tanto que a la sociología se le asignan las sociedades de la modernidad. Identificar a las poblaciones de los territorios coloniales como etnias se hacía según los criterios de los estados europeos, es decir, desde una visión etnocéntrica de la otredad, asociada con la inferiorización cultural y/o civilizatoria que justificaban, política e ideológicamente, los procesos de subordinación, dominación y explotación. En las ciencias sociales el término etnicidad aparece a mediados del siglo XX, particularmente en la literatura anglófona para designar a los grupos angloamericanos; y en las disciplinas sociales francesas la etnia aparece muy tardíamente, en el transcurso de los años ochenta, a causa de la desconfianza que les generaba el empleo de este término².

La incorporación de los conceptos de etnia y etnicidad en las ciencias sociales trajo consigo la construcción de importantes programas de investigación que desde diferentes enfoques se propusieron definir y delimitar el nuevo campo de investigación, vinculados a los proyectos y políticas de los estados nacionales así como a los procesos migratorios asociados a la industrialización, modernización y globalización. Desde la Grecia antigua, sin embargo, algo se ha mantenido constante en la definición de las etnias desde el poder académico o político: el referente a la diferencia y la otredad del designado respecto del identificador y clasificador.

Por otra parte, el surgimiento de movimientos sociales y de reivindicación étnica y política entre las poblaciones caracterizadas como étnicas, ha conducido a procesos de redefinición de los usos y significados de ser etnia, al tiempo que ha propiciado el surgimiento de posicionamientos específicos acerca de cómo debe ser la inserción de las etnias dentro de los Estados nacionales, en un contexto en el cual estas exigen derechos propios: la integración y la homogeneización cultural o la persistencia y el derecho a la diferencia cultural.

En el campo de la definición de lo étnico esto ha generado situaciones en las que a veces entre los académicos, los políticos y los actores sociales hay concordancia y a veces oposición en la definición de lo étnico.

Para fines de una mej or comprensión, las diversas posiciones sobre el carácter de lo étnico, se pueden agrupar esquemáticamente distinguiendo una visión que lo naturaliza respecto de aquella que lo considera producto de una construcción social ${ }^{3}$.

Las vertientes que se enmarcan dentro del esencialismo parten por considerar lo étnico, y su concreción en la etnicidad de un grupo particular, como un hecho social que existe independientemente del sujeto que la porta, lo analiza o lo utiliza; lo que varía en estas posiciones es el carácter de ese hecho social: que puede ser ontológico en la medida que se considera como una manifestación de un ser biológico, o primordial si se cree que es expresión de un ser cultural, según la cual las etnias se basan en vínculos o afinidades primordiales como las que congregan a las unidades familiares y a los llamados "grupos primarios"; mismos que deben distinguirse de los vínculos meramente civiles.

2 Rouland, Pierré-Caps y Poumarède (1999). Gilberto Jiménez, por su parte, en su artículo publicado en este libro “El debate contemporáneo. En torno al concepto de etnicidad", señala que según ciertos autores el concepto de "etnicidad fue introducido por el sociólogo norteamericano David Reisman en los años 50; mientras que para otros su introducción se debe a W.L. Warner, coordinador de la serie Yankee City Series.

3 Se trata de una tipología que permite advertir tendencias, ej emplificadas con algunos autores, sin que ello signifique encasillarlos. Tampoco se pretende hacer un listado que agote a todos los autores que pueden inscribirse en una u otra tendencia. 
UNIVERSIDAD CATÓLICA DE TEMUCO

\begin{tabular}{|c|c|}
\hline $\begin{array}{l}\text { LA NATURALIZACIÓN DE LA } \\
\text { ETNICIDAD }\end{array}$ & $\begin{array}{l}\text { LA ETNICIDAD COMO } \\
\text { CONSTRUCCIÓN SOCIAL }\end{array}$ \\
\hline $\begin{array}{l}\text { Lo étnico como hecho social. Se concibe } \\
\text { la existencia de un ser-esencial que } \\
\text { condiciona rasgos característicos (culturales, } \\
\text { lingüísticos, históricos) y que son base de la } \\
\text { etnicidad y de la conciencia de la identidad } \\
\text { étnica. } \\
\text { La etnicidad es un hecho social, un referente } \\
\text { primordial, que debe ser descubierto y } \\
\text { analizado. } \\
\text { Esencialismo } \\
\text { - Ontológico: etnicidad inmanente a la } \\
\text { naturaleza humana, que se expresa en } \\
\text { formas determinadas biológico-culturales de } \\
\text { un grupo (Van der Berghe); } \\
\text { - Primordialista: etnicidad como expresión } \\
\text { de un ser cultural (Shils, Geertz, Isaacs); } \\
\text { - Reduccionista: la etnicidad tiene } \\
\text { correspondencia directa con una } \\
\text { determinada posición social (clase, por } \\
\text { ejemplo). } \\
\text { antecedió y que es garante de la identidad } \\
\text { étnica específica. }\end{array}$ & $\begin{array}{l}\text { Lo étnico como construcción social implica } \\
\text { clasificación (visión diacrítica y relaciona), } \\
\text { asociada a la construcción identitaria, y } \\
\text { de la otredad, de lo igual y de lo diferente } \\
\text { (autodefinición y heterodefinición). } \\
\text { Es hecho social, producido por la clasificación } \\
\text { cognitiva y por la acción social. } \\
\text { Vertientes: } \\
\text { 1) Etnicidad como estrategia: } \\
\text { - Instrumental, como un hecho social } \\
\text { (Cohen). } \\
\text { - Acción racional, como hecho individual } \\
\text { 2) Etnicidad como invención: } \\
\text { - Inventada (Anderson, Ranger). } \\
\text { - Comunidad moral (Yeros). } \\
\text { 3) Etnicidad como identidad y/ o política } \\
\text { de la diferencia (Barth, Cardoso, Bonfil, } \\
\text { Giménez, Bartolomé, Poutignat y Streiff- } \\
\text { Fenart, Gros, Varese). } \\
\text { - Construcción colonial (Gibson-Graham) } \\
\text { - Desterritorialización (Oommen) }\end{array}$ \\
\hline
\end{tabular}

Por su parte las posiciones constructivistas, pese a su diversidad, tienen en común el principio de que los fenómenos étnicos se producen socialmente, ya sea que se expresen como categoría de pertenencia (grupos de adscripción e identidades sociales), como categorías de conocimiento y clasificación, o como hechos producidos por la acción intersubjetiva de los actores; como consecuencia, y con consecuencias, en las relaciones y prácticas sociales.

Los autores que consideran que un grupo étnico existe en cuanto hecho objetivo se diferencian de las posiciones esencialistas, en que para ellos tal grupo no existe por la predeterminación de un ser-esencial, sino por la acción social (objetiva y subjetiva); de modo que se trata de hecho social contextual, cambiante, aunque no ajeno ni independiente de los sujetos, quienes toman decisiones y actúan sobre ese hecho para generarlo, reproducirlo o modificarlo. Aunque también existen quienes consideran que la etnicidad es una ficción analítica, en la medida que no es independiente del analista que la estudia y la constituye.

Los que conciben la etnicidad como estrategia, privilegian ante todo su empleo para la obtención de ciertos fines: para los instrumentalistas es un recurso colectivo al que 
recurren ciertos grupos de interés, y en esa medida es manipulable con el fin de obtener determinados recursos materiales y simbólicos; mientras que para los que sustentan la etnicidad como producto de la acción racional, el énfasis está puesto en la acción de los individuos que actúan con el fin de maximizar sus beneficios en ámbitos en los que los bienes son limitados. De modo que estos son capaces de utilizar sus características físicas y culturales para crear fronteras y categorías sociales desde los cuales incluir o excluir a individuos y grupos en la competencia por ciertos recursos.

Los que piensan la etnicidad como producto imaginado ponen énfasis en explicar los procesos históricos mediante los cuales han surgido los sentimientos de pertenencia a una colectividad. Algunos la consideran imaginada o inventada en la medida en que es producto de una creación colectiva que surge en determinadas condiciones históricas y en el contexto de relaciones sociales y de poder específicas. Otra vertiente de esta posición es la de aquellos que ven la etnicidad como comunidad moral, normativa, creada en el contexto de actores heterogéneos en conflicto y que se disputan el dominio moral de los derechos y las obligaciones, así como de las inclusiones y exclusiones del grupo. En ambos casos, no se trata de hechos racionales e individuales, y por ello, es importante analizar los hechos poniendo en evidencia los factores objetivos e intersubjetivos de sus orígenes y expresiones sociales.

Los que enfatizan lo étnico como sustento para la construcción identitaria sustentan su posición en una visión diacrítica y relacional presente en la construcción de las categorías sociales de adscripción y pertenencia, y que está asociada a procesos de autoclasificación y heteroclasificación, de definición de lo igual y lo diferente, y de decisión sobre la inclusión-exclusión; procesos que se desarrollan en el marco de las acciones constitutivas de la identidad y de la diferencia. Para ellos, importa, por tanto, conocer la historicidad y la contextualización de la producción de estas identidades, así como los procesos de subjetivación que las posibilitan y que producen a los sujetos étnicos. En contextos de asimetría social, en que las relaciones de poder crean condiciones de subordinación, discriminación y exclusión entre grupos sociales, deriva en que las identidades sean relacionales con los consecuentes elementos ideológicos y de representación social que los acompañan. Dentro de los autores incorporados a esta perspectiva general, sin embargo, hay una gran variación en cuanto a los elementos que caracterizarían a un grupo étnico: algunos ubican el carácter definitorio en la historicidad previa, de tales grupos, a los estados nacionales; otros, en las referencias que los grupos étnicos hacen a la ascendencia como marcador de la inclusión y exclusión; y otros más en el tipo particular de cultura e identidad que portan; e incluso, hay quienes definen a un grupo étnico, no por unas $u$ otras cualidades culturales e identitarias, sino porque son portadores de una cultura y una identidad que se mantiene y reproduce en oposición a otras que son las dominantes.

Otra vertiente, cercana a la identitaria, es la que incorpora la dimensión de la dominación como generadora de etnicidad. Las posiciones deconstructivistas (Derrida y Foucault, 1989) presentes en los estudios postcoloniales, enfatizan la importancia de descubrir la trama de la articulación entre los proyectos coloniales y la construcción étnica, misma que se realiza mediante la construcción de la otredad, empleando como referente positivo la visión eurocentrista y occidental de la identidad, y como negativa, la identidad étnica, que por lo mismo queda en una posición desigual y subordinada. Para quienes apoyan esta vertiente, la deconstrucción es una estrategia para acabar con la estructura binaria propia de la generación de etnicidad, y se proponen hacerlo por dos vías: mediante la valoración de las identidades subordinadas, y acabando con las fronteras identitarias así como con la estabilidad entre los elementos presentes en la estructura de oposición y dominación. 
Dentro de las tendencias que enfatizan la dominación, están los que señalan los procesos de desterritorialización como generadoras de etnicidad, y que señalan una más amplia gama de procesos de dominación: los que están presentes en la colonización, en la formación de los estados nacionales, en las guerras de invasión, en las migraciones internacionales y en todos los proyectos de homogeneización e imposición cultural. Para ellos son estas condiciones las que han posibilitado, tanto en el pasado como en el presente, que diversas poblaciones, o comunidades culturales, sean etnicizadas, al despojarlas por diversas vías de su territorio (por lo general mediante formas violentas) creando la ruptura o atenuación de sus vínculos (físicos, morales y simbólico-expresivos) con sus territorios ancestrales; lo cual, según ellos, es lo que desemboca en la desnacionalización, la marginalización, el extrañamiento y la expoliación de las mismas. La etnicización, por tanto, más que basarse en la existencia de ciertos elementos y características propios del grupo, o de la población etnicizada, se construye en el proceso mismo mediante el cual esa colectividad es percibida y definida como foránea, creando hacia ella, y en ella, un sentimiento de inferiorización.

\section{Aportaciones y retos en la definición de lo étnico}

Con todas las limitaciones que conlleva hacer un balance sobre los aportes y tareas pendientes, se pueden señalar ciertos aportes que contribuyen a dilucidar viejos problemas y a fortalecer nuevas perspectivas sobre la definición de lo étnico.

Un primer elemento que apunta a generalizarse dentro de la amplia gama de trabajos que se desarrollan actualmente en relación con lo étnico, es el rechazo a las definiciones que naturalizan y esencializan la etnicidad, que son ahistóricas y esencialistas, o que privilegian solo la dimensión estratégica de la etnicidad. Respecto de estas últimas, si bien se reconoce la posibilidad de que las identidades sean empleadas individual 0 colectivamente para lograr ciertos fines, y que incluso sean manipuladas con intereses determinados, se considera que estos hechos no pueden ser el rasgo definitorio de la etnicidad, ya que todas las identidades, incluyendo las étnicas, comprenden además, de esa dimensión utilitaria (racional e irracional, y actuada de forma individual o colectiva) elementos de pertenencia, valorativos, cognitivos, simbólicos y emocionales, entre otros.

La tendencia mayoritaria, en cambio, es a desarrollar posiciones constructivistas, opositoras a la naturalización de la etnicidad, que privilegian su historicidad, en la medida en que se pone atención en los procesos discursivos y no discursivos de la construcción de la diferencia, como fundamento constituyente de las identidades sociales. De esta forma, se fortalece la tendencia de comprender la etnicidad en el marco de la construcción identitaria; e incluso, están abiertos los caminos para comprender la existencia de los grupos étnicos como resultado de procesos particulares de etnicización.

Un segundo elemento es el principio cada vez más generalizado de que las poblaciones denominadas étnicas son incomprensibles sin las necesarias referencias al colonialismo, al papel de los Estados, a las migraciones y a la dominación, ya que son procesos que inciden en su constitución y sus transformaciones, incluyendo el hecho de que a partir de esos elementos ciertas poblaciones sean caracterizadas como etnias y otras no.

Vinculado a lo anterior, surge la necesidad de que la gran diversidad de pueblos caracterizados como étnicos deba analizarse en los contextos de las relaciones de poder en las que están inmersos, tanto interna como externamente. De ahí la importancia de atender los procesos de subordinación, explotación y exclusión; así como la creciente necesidad de comprender mejor las relaciones entre etnia y clase, dentro de una perspectiva capaz de superar la estrechez economicista derivada del marxismo ortodoxo, pero también 
dejar atrás la inconsistencia de los postulados extremos postmodernos. Una posible vía es la que ensayan los autores que construyen una articulación entre el concepto marxista de explotación y el concepto funcionalista de clase -que la define en tanto grupo de estatus-, y que buscan explicar situaciones en las que los rasgos de estatus -como los de raza, cultura o género- posibilitan la exclusión, la dominación y la explotación económica (Vilas, 1990).

Un tercer elemento significativo, es que en la actualidad predomina la definición de cultura como dimensión simbólica, con lo cual se superan las definiciones culturalistas, funcionalistasy mecanicistas anteriores, lo cual pone las bases para comprender las relaciones entre la identidad y la cultura; sería posible, por tanto, superar la confusión tan común que las equipara y las trata como equivalentes, estableciendo, por tanto, qué es lo que marca las diferencias entre una identidad y una cultura. Es decir, ahora se pueden percibir con mayor precisión las diferencias entre los procesos constitutivos de una identidad, como una construcción social, de lo que es la cultura que da sustento y provee de emblemas, de marcas simbólicas, a esa identidad. En el marco de los estudios sobre etnicidad, ello es una contribución para limitar las visiones que la naturalizan, al concebirla como producto de un ser preexistente (biológico o cultural), o que la sustancializan al asociarla únicamente con la ausencia o presencia de ciertos rasgos culturales, que son los que la predeterminan y definen.

Un cuarto elemento importante, es que se ha dejado atrás la oposición antagónica entre lo tradicional y lo moderno y las consecuentes tendencias unilineales y unidireccionales del cambio cultural. Con ello se dejarían las posiciones que consideran inevitable el tránsito de las comunidades étnicas hacia las sociedades urbanas modernas y que perciben la homogeneización cultural como el resultado universal y deseable para las sociedades contemporáneas.
El foco de atención, en cambio, ha girado de forma importante hacia comprender, mediante la deconstrucción, los fundamentos del pensamiento colonial fundados en la estructura binaria de oposición y exclusión entre identidades positivas y negativas, que sustentan una particular modalidad de dominación basada en la estrategia de construcción de la otredad. En esta posición, más que en fortalecer la estructura de oposición, esta perspectiva se inclina por la ruptura de las fronteras, el fin de la dicotomía de la alteridad característica del pensamiento colonial (Restrepo, 2004).

Y quinto y último elemento de gran importancia es que los actores étnicos participan hoy activamente en el debate académico y político, que se ocupa de establecer el lugar de las poblaciones étnicas dentro de los estados nacionales y dentro de la sociedad mundial, y aún en el debate que se preocupa por establecer cuáles son los elementos constitutivos de la etnicidad. En este punto destacan dirigentes de movimientos sociales así como los académicos inscritos en la perspectiva postcolonial.

\section{Hacia la comprensión de lo étnico}

La cultura en la construcción de las fronteras identitarias

En las actuales condiciones de discusión sobre lo étnico, cabe ir estableciendo acuerdos que permitan establecer con claridad definiciones conceptuales y crear consensos.

Un aspecto sobre el que hay que llegar a un acuerdo es sobre la construcción de las fronteras étnicas.

Fredrick Barth (1976), como se sabe, subrayó la importancia que tiene la construcción de las fronteras en la delimitación étnica, así como en el papel que juegan en ello la acción recíproca entre grupos y la selección de ciertos rasgos de la cultura seleccionados por los grupos en interacción para definir las fronteras. En América Latina, 
Cardoso de Oliveira $(1992,1998)$ enfatizó, por su parte, la importancia de atender las condiciones de desigualdad y asimetría en la construcción de las fronteras étnicas; se acerca a las aportaciones de las perspectivas postcoloniales que apuntan a desentrañar el papel de la dominación en la construcción étnica.

Aunque cierta lectura de la obra de Barth condujo en América Latina a la creencia de que los grupos étnicos son ante todo una forma de organización social, identificada particularmente con rasgos heredados de los pueblos prehispánicos, es indudable que Ios aportes de Barth permiten comprender que no toda la cultura es significativa para la delimitación de las fronteras étnicas, que las fronteras son permeables y cambiantes lo mismo que los elementos culturales 0 emblemas que las definen, y que se establecen como producto de la interacción entre un "ellos" y un "nosotros", entre la inclusión y la exclusión, entre la autoadscripción y la heteroadscripción.

Después de tales aportes ya no es posible, por tanto, equiparar mecánica y descriptivamente una identidad con la cultura de un grupo étnico: es decir, ya no se pueden tratar como equivalentes una identidad y una cultura, ni puede considerarse que un cambio en la cultura significa un cambio automático en la identidad ni que un cambio de identidad origina un cambio automático en toda la cultura.

En efecto, la relectura cuidadosa de la obra de Barth, sumada a la definición simbólica de la cultura y a los avances en la teoría de las identidades sociales, permite fortalecer nuevos enfoques.

En términos generales, la cultura dentro de la perspectiva simbólica, es un repertorio de pautas de significado que son las que le dan un sentido y un valor específico a las acciones y a las formas de vida de un grupo social, en un tiempo y un lugar determinado, y se expresa tanto en formas objetivadas como en formas interiorizadas; dimensiones de la cultura que permiten entender que todo lo material e inmaterial, lo natural y lo social, tienen significado y se expresa en las decisiones y acciones de los sujetos (Geertz, 1992) (Giménez, 2000). La identidad en este marco es, por tanto, una unidad de pertenencia e identificación, que establece la mismidad y la otredad, las normas de inclusión y exclusión, así como las formas de autoidentificación y de denominación de los externos; y para cuya construcción sus integrantes ponen en acción su cultura, con el fin de construir la organización social de la diferencia.

Tal interpretación sostiene la idea de que desplaza el interés taxonómico - de cotejar y establecer rasgos culturales, de organización social y aun de historia- para definir un grupo étnico, hacia la construcción interactiva y subj etiva de las fronteras sociales: es decir, hacia la construcción simbólica y la organización social de las diferencias (Giménez, 2000; Poutignat y Streiff-Fenart, 1995; Pérez Ruiz, 2004).

Lo anterior permite, a su vez, hacerse la pregunta fundamental acerca de si el carácter interactivo y relacional en la construcción de las fronteras -que incluye los procesos de autoadscripción/ heteroadscrición, los de inclusión/exclusión, así como los de autodeterminación/ heterodenominación (Giménez, 2000, 2003) son procesos exclusivos en la construcción y delimitación de los grupos étnicos: es decir, si estos son los elementos exclusivos que definen su carácter étnico, o si, por el contrario, estos procesos son comunes a la construcción de cualquier identidad social.

La dominación en la construcción étnica

En esta perspectiva, la identidad se construye relacionalmente dentro de marcos sociales de interacción que determinan la posición de los actores, y en que participan elementos objetivos y subjetivos. Los elementos que muchos autores usan para definir una identidad étnica son, en efecto, 
Ios componentes de toda identidad social:

-Es una construcción social: no es esencial ni ahistórica y es cambiante.

-Se genera en la autoadscripción y heteroadscripción, es relacional e importan las relaciones asimétricas implicadas en su construcción.

-Emplea repertorios culturales para marcar fronteras y distinguir (se) o distinguir a los otros.

-Puede ser utilitaria y estratégica, aunque la identidad no se agota ni se reduce a tales procesos.

Al ser así, queda sin resolver qué es lo específico de las identidades étnicas, con lo cual su búsqueda se desplaza hacia el análisis de los procesos y condiciones que posibilitan la construcción subjetiva de la diferencia étnica. Pudiendo identificarse dos vías para hacerlo: la de las cualidades culturales y la de la dominación. Ante las dificultades para acordar los elementos culturales definitorios de lo étnico, ya sea porque no todos los grupos caracterizados como étnicos comparten los rasgos empleados como definitorios, 0 al contrario, porque todos, incluyendo a los no étnicos, los comparten, queda por explorar el papel de la dominación, bajo el acuerdo generalizado de que los grupos étnicos tienen en común su condición minorizada y subordinada.

Si atendemos al origen del concepto así como a la forma en que se ha empleado la denominación de lo étnico, podemos considerar que lo que tienen en común los diferentes grupos llamados étnicos no es que posean ciertos caracteres objetivos - de tipo cultural, identitario u organizativo- ni tampoco que posean una cierta forma de relación con el territorio, ni que sean anteriores o producto de los estados nacionales, sino que son llamados así como producto de una construcción política y social de las diferencias sociales, que los ha clasificado como "otros" desde la perspectiva del grupo y/o la sociedad dominante. De allí que en general se diga que son etnias y poseen culturas étnicas solo poblaciones y grupos dominados, es decir, que han sido "etnicizados" por aquéllos que, desde el poder político, económico y aun académico los han caracterizado como diferentes sobre la base de sus rasgos culturales, religiosos, identitarios, e incluso raciales, a pesar de que tales diferencias, o el grado de tales diferencias, no sean significativas, cuantificables, o cotejables empíricamente. Con esto no se quiere decir que tales poblaciones sean inexistentes, o que no puedan ser portadoras de características culturales e identidades específicas; por el contrario, es posible que, incluso, como las de origen prehispánico tengan una existencia anterior a los estados nacionales, o que mantengan la ancestralidad como elementos constitutivos de su identidad. Estos elementos, sin embargo, no son los que los caracteriza como étnicas; Io que los determina es que tales elementos, en ciertos contextos, sean exaltados y empleados para minorizarlas, para convertirlo sen "otras". Un proceso de etnicización puede realizarse sobre poblaciones que no guardan vínculos organizativos entre sí (como cuando grupos de inmigrantes se les denomina "hispanos", "afros" o "asiáticos") o sobre grupos sociales cohesionados organizativa y culturalmente, como cuando se etniciza un pueblo particular mediante la colonización o la invasión.

Tal proceso de organización social de la diferencia puede incluir la imposición de una nueva adscripción identitaria para el etnicizado (como sucedió para los fines de la conquista y la colonización cuando se denominó indios a una gran cantidad de pueblos prehispánicos), o puede emplearse la identidad propia del subordinado, exaltando sus peculiaridades para marcar las diferencias con fines de subordinación.

Hay que decir, sin embargo, que del proceso de dominación, y mediante la internacionalización de la diferencia, también es posible que emerjan grupos con identidades étnicas en donde antes había poblaciones dispersas, precisamente como sucede entre hablantes de alguna lengua que al ser etnicizados y construidos como grupos, terminan por configurarse como 
tales, emprendiendo, incluso, movimientos sociales de reivindicación. Es decir, que a partir de que cierta población ha asumido e interiorizado la heterodenominación hecha por un grupo dominante, esta no sirva solo para la dominación, sino que es posible que dicho grupo se la apropie y la resignifique como elemento valioso para la acción social. Estos procesos, que actúan como sustrato de la clasificación étnica, son explicables solo profundizando en lo que algunos autores han llamado el "poder configurativo de la denominación".

El poder configurativo de la denominación y los procesos de exclusión y discriminación

Cuando una población se denomina desde el exterior como étnica, y tal denominación se acompaña de prácticas sociales hegemónicas que la ubican y reproducen en cierto lugar de las relaciones sociales, suele presentarse como si tal clasificación diera cuenta de un hecho natural y objetivo, y se ocultan los procesos mediante los cuales se construye la organización social y simbólica de las diferencias así como los mecanismos que operan para imponerla.

Sobre este tema, hay avances que indican que la definición exógena impuesta recubre los procesos de clasificación y etiquetación en virtud de los cuales se asigna a un grupo una identidad étnica desde el exterior ${ }^{4}$. Según autores como Poutignat y Streiff-Fenart (1995) el hecho de la nominación, de nombrar al otro, en contextos de asimetría y dominación, constituye un aspecto revelador de las relaciones interétnicas, en la medida que evidencia uno de los mecanismos de la etnicización, al tiempo que es en sí mismo un hecho productor de etnicidad. Es decir, que en situaciones de dominación, la imposición de una etiqueta por parte del grupo dominante tiene un poder preformativo, ya que el hecho de nombrar tiene el poder de hacer existir en la realidad y mediante diversos mecanismos sociales, a una colectividad de individuos, sin que importe que los individuos, así denominados, se autodenominen de otra forma, tengan otra identidad, o incluso se opongan a su pertenencia a esa nueva colectividad.

De esta forma, es posible que, en ciertos contextos de dominación, la definición exógena sea la única que opere, negándole a una colectividad, o a ciertos pobladores, su identidad anterior y con ello el derecho de definirse por sí mismos, o que opere la heterodenominación impuesta, en interacción y aun en oposición permanente con al autodenominación; situación que propicia la interiorización de la inferioridad y la estigmatización de la identidad propia subordinada.

Llama la atención que los mecanismos psicosociales básicos que subyacen en la producción y atribución de identidades sociales mediante operaciones recíprocas de reconocimiento (Giménez, 2003), incluyan los procesos de discriminación y exclusión. Algunos elementos que se retoman de este autor, y que hay que tomar en consideración para el análisis de lo étnico, son:

1) Que toda discriminación social comporta un intercambio recíproco, pero desigual, de reconocimientos evaluativos entre actores sociales que ocupan posiciones dominantes y dominadas en el espacio social.

2) Que de aquí resulta un intercambio desigual de valores (cualitativos) que tiende a generar un tipo particular de conflictos llamados "conflictos de reconocimiento", analíticamente distintos de los conflictos de interés y de los ideológicos.

3) Y que la discriminación social es una actitud culturalmente condicionada y negativamente orientada de los grupos dominantes hacia los grupos 
dominados, misma que en los procesos de interacción/comunicación se traduce en comportamientos de hostilidad y trato desigual de los individuos dominantes respecto a los individuos dominados. La discriminación, entonces, puede implicar también la segregación (residencial y laboral) y, en instancia extrema, la exclusión pura y simple, como ocurre en los casos de deportación o de destierro.

De esta forma, la construcción de los estereotipos, de los prejuicios hacia ciertos grupos, en ciertas circunstancias puede ser hasta cierto punto "inofensiva" y hasta "neutral" (Giddens, 1993), en otras, donde predomina la hostilidad, la inseguridad, el miedo, se expresaría en conductas hostiles y de odio, en suma, xenofóbicas.

\section{Lo étnico. Una propuesta}

Sobre la base de los elementos anteriores, se puede concluir que lo específico de lo étnico es que corresponde a una forma de clasificación social, a partir de la cual se organizan las diferencias culturales entre grupos sociales que establecen relaciones en condiciones asimétricas, y en la cual se emplean estas para marcar, establecer las fronteras y explicar y justificar tanto las relaciones asimétricas y de dominación como para emprender acciones que reviertan tal situación. Es por tanto una forma de clasificación, de enunciación y de dominación que emplea la diferencia cultural para construir identidades estigmatizadas y negativas que generalmente se impone, desde el poder y desde el exterior, sobre poblaciones, grupos e individuos con características raciales, identidades y culturas propias. Se trata de un proceso de etnicización que implica el poder de configurar un grupo social mediante la enunciación de su existencia y la definición de sus atributos y características culturales, en donde había colectividades que se autodefinían y caracterizaban de forma diferente, y aun en donde había individuos dispersos sin sentido de colectividad y sin organización social como grupo. Tal enunciación se expresa en acciones, en diferentes ámbitos de la vida social, mediante las cuales se pasa del decir al hacer para construir, reconfigurar, reubicar, integrar o anular a los grupos étnicos en cuestión. El carácter de grupos étnicos, en su bipolaridad con los no étnicos, los coloca en un lugar subordinado en la organización social de las diferencias sociales, y les impone un estigma de inferiorización a sus identidades previas.

Así, un grupo étnico solo existe en relación con y en interacción con un grupo dominante que lo clasifica y minoriza empleando para ello la diferencia cultural, por lo cual su carácter de ser étnico no se debe a su naturaleza ni se corresponde con sus cualidades culturales en sí mismas, más que en la medida en que ellas son empleadas para marcar las diferencias respecto del dominador. Tampoco el carácter étnico de un grupo se fundamenta necesariamente en que su historicidad sea previa a los estados nacionales, ni en que posea una identidad propia sustentada en su ancestralidad y/ o en emblemas de su cultura tradicional. Menos aún se ancla en su homogeneidad cultural, en su aislamiento geográfico, o en su inmovilidad cultural. Y si bien sus elementos culturales, su primordialidad y su identidad propios son tomados como referencia, como base para la etnicización, no son estos en sí mismos los que lo constituyen como étnico, sino el que esté inmerso en una relación de desigualdad, asimetría y dominación, y donde existe una contienda por el reconocimiento.

La estigmatización negativa sobre la cultura y la identidad propias de los dominados puede conducir a que esta se interiorice -tanto en el dominador como el dominado- y que por tanto el carácter de "otro" minusvalorado se asuma como cualidad inherente y definitoria del ser cultural del etnicizado. Ello puede conducir: a que el dominado abandone su cultura y la identidad con la cual se le ha caracterizarlo como étnico y que asuma la cultura y la identidad del dominador; a que el dominado oculte y repliegue lasmanifestaciones 
de su cultura y su identidad propias, las cuales mantiene en resistencia, al tiempo que aprende las pautas culturales e identitarias del dominador; o que engendre un rechazo defensivo contra la cultura del dominador, y que se movilice contra ellas. En este último caso, las poblaciones minorizadas pueden revalorar sus culturase identidades etnicizadas para emprender procesos de reivindicación de derechos. $Y$ en los casos extremos, en los que es mediante la dominación y la imposición de una nueva identidad estigmatizada que se les configura como grupos, estos pueden asumirse como tales, y en un proceso de etnogénesis, movilizarse como actores étnicos en la lucha por derechos específico. Este caso lo podemos ejemplificar con la reapropiación que los diferentes pueblos originarios de América han hecho de la identidad como indígenas -con una connotación colonial y negativa- para transformarla en una identidad aglutinadora y movilizadora para reivindicar el derecho a la diferencia dentro de los estados nacionales. Por ello, se puede afirmar que la configuración étnica en un grupo, si bien requiere para existir de una relación asimétrica y de dominación, esta puede generarse desde el poder, para fines de subordinación, exclusión o integración, o desde la población misma subordinada que se construye y organiza como grupo cultural e identitario para defenderse y responder a tal dominación.

Si se está de acuerdo con lo anterior, lo étnico, y por lo tanto el ser étnico, es una construcción social en la medida que es una cualidad, un valor, una característica, una connotación que se agrega, se asigna o se impone sobre las culturas e identidades de poblaciones minorizadas, usándose para ello la diferencia cultural. La etnicización, y con ella la diferencia cultural, se emplea tanto para justificar la dominación como para emprender acciones de movilización contra esta.

En ese marco, las diferencias culturales empleadas para marcar las fronteras entre poblaciones consideradas étnicas y las no étnicas, pueden ser reales o imaginarias y pueden referirse solo a un rasgo, al conjunto de la cultura o a la identidad como expresión articulada de la diferencia. Así, Ias diferencias de identidad, de raza, de lengua, de cultura e incluso de civilización emergen como atribuciones (o cualidades) culturales sobre las que se acentúan las diferencias (reales o imaginarias), sustentando la dominación y generando la segregación y/ o la exclusión.

De esta forma, la interacción asimétrica y desigual entre grupos sociales con culturas e identidades diferentes es condición para que se construya un "otro" minorizado y estigmatizado y que este adquiera el carácter de grupo étnico. Cuando la interacción se desarrolla en condiciones de simetría, o de competencia horizontal, y ninguna población etnicizará a la otra, y las fronteras culturales e identitarias establecidas tendrán como finalidad mantener las especificidades propias de cada grupo, se podrá decir que dichos grupos han establecido relaciones interculturales entre ellas y no relaciones interétnicas.

Cabe decir, además, que la dominación cultural implantada mediante la clasificación étnica del otro no excluye la presencia de otro tipo de dominación y que, por el contrario, generalmente se emplea para fundamentar y justificar otro tipo de relaciones de subordinación, de explotación o de exclusión. Así, la dominación étnica puede ejercerse sobre poblaciones socialmente homogéneas o estratificadas y clasistas, sin que ello sea condición ni impida el ejercicio de la dominación cultural. De lo anterior deriva la necesidad de diferenciar la dominación étnica de la dominación de clase, aunque en determinados momentos y condiciones puedan coincidir ambos tipos de dominación en un mismo grupo social.

La identidad étnica, entonces, sería aquella dimensión clasificatoria que se impone sobre las identidades de los dominados que las hace extrañas y diferentes a la de los opresores; y que, como en el caso de América, puede inclusive llegar a construir una identidad sobrepuesta, homogeneizante, que une a todos 
los dominados -a pesar de su diversidad de culturas e identidades- en un solo grupo en el que se omiten los rasgos culturales específicos. En ese proceso extremo se crea, entonces, una identidad imaginada que estigmatiza una serie de rasgos (reales o imaginados) entre los dominados para marcar las diferencias entre los oprimidos y los opresores (los indios son producto del diablo, herejes, caníbales, flojos, atrasados, incivilizados, feos, inmorales, mal vestidos, incultos, etc.).

Cuando los grupos oprimidos por la dominación étnica emplean la identidad que se les impone para unir a la diversidad de los que han sido etnicizados en contra del grupo opresor, es cuando el proceso se invierte: son los oprimidos los que desde sus particularidades culturales e identitarias recrean, inventan 0 invierten los estigmas de la identidad étnica común empleada para sojuzgarlos. Le dan así otros contenidos, otro valor, y forman su propia visión de la identidad étnica que Ios unifica: la identidad indígena, revalorada y positiva es, entonces, depositaria del imaginario que emplean los dominados para su movilización social: los indios son sabios, son armónicos con la naturaleza, son guardianes de saberes y misterios ancestrales, son justos casi por esencia, son, además, los dueños ancestrales de la tierra, todos son explotados y discriminados por igual por los no indígenas y tienen grandes cosas que enseñarles a los no indios respecto de la democracia, la justicia y la humanización de las relaciones sociales. Muchos de esos elementos que se emplean en las luchas de reivindicación étnica en ocasiones poco tienen que ver con la realidad de las culturas y las identidades de las comunidades a nombre de las cuales se combate. Pero, de cierta forma, son indispensables para lograr contundencia y fuerza en la batalla por las representaciones sociales -contra el dominador-para lograr cambiar la organización social de las diferencias culturales, que no les favorecen; es un mecanismo, en suma, para conseguir, de parte del Estado y la sociedad nacional, el reconocimiento positivo de sus peculiaridades e identidades propias.
Debido a que la lucha étnica es una batalla por el reconocimiento, por el respeto a la diferencia cultural, esta es insuficiente para resolver los problemas derivados de otro tipo de desigualdades como la de clases sociales - las de género. Cada tipo de desigualdad tiene su propia lógica de dominación y de reproducción, tiene sus agentes particulares y sus ámbitos institucionales para hacerlo, aunque en la cotidianidad todas esas formas de dominación y de desigualdad se mezclan, se confunden y unas se sirven de otras.

Las relaciones entre la dominación étnica y la de clases no se presentan ni se desarrollan de la misma manera entre todos los grupos ni en todos los momentos de la historia. Las particularidades que adquieren los procesos dependen, en cambio, de las condiciones de los pueblos que entran en contacto en condiciones significativas de asimetría y desigualdad.

En síntesis, la caracterización y clasificación de una población como étnica es una construcción social, puesto que ningún grupo en especial ni tampoco ninguna población en general tienen como característica inherentes esa condición; es un atributo de carácter histórico que se le impone al otro y que adquiere características específicas según sean las condiciones históricas y coyunturales en que se produce la etnicización; y esta se genera en la interacción entre grupos sociales en condiciones de desigualdad social, por lo cual implica una situación relacional y asimétrica. De esta forma, no toda identidad de un pueblo o grupo social es étnica; no es étnica cualquier forma de subordinación, no cualquier grupo subordinado puede ser considerado étnico, y lo étnico no puede predefinirse a partir de la existencia de ciertos rasgos culturales, raciales e identitarios de la población. No está de más señalar que la confrontación étnica en los casos extremos adquiere un tinte de conflicto, de guerra, entre civilizaciones. 
UNIVERSIDAD CATÓLICA DE TEMUCO

\section{Para abordar viejos problemas}

Cuando no se reconoce que el carácter étnico de una población es un atributo de clasificación que se impone en condiciones de asimetría y desigualdad -y que por tanto no se origina en ningún atributo cultural, identitario, u organizacional específico- se generan dos problemas fundamentales:

a) Que se oculten lascondicionesde asimetría y de desigualdad que condicionaron el surgimiento de tal clasificación; y

b) Que lo étnico se naturalice y se sustancialice, al percibirlo como parte inherente de la cultura y la identidad del grupo etnicizado.

c) De la sustancialización de lo étnico como cualidad cultural surge a la vez la confusión que propicia que cuando se habla de lo característico de cierto grupo étnico, se mencionen sus cualidades de identidad y cultura (lo étnico, la etnicidad, se emplea como equivalente de peculiaridad cultural), y se omita desentrañar la construcción de la diferencia mediante la cual ha sido minorizado y clasificado como étnico. De allí que ante la diversidad de grupos culturales etnicizados, la definición de lo étnico mediante rasgos culturales no tenga salida alguna, y suceda que quienes intentan esta vía terminen haciendo listados descriptivos de rasgos culturales para decidir qué grupos son y cuáles no son "étnicos".

d) Sumado a lo anterior, existe el desconocimiento que lleva a confundir la identidad propia de un grupo, con la identidad agregada que puede imponérsele al etnicizarlo. De allí que cuando se habla de la identidad de un pueblo originario de América se hable de su identidad indígena, sin mayor distinción respecto a la identidad tal y como esa población de autodenomina, y sin que se distinga el carácter impuesto y colonizador de la identidad indígena, que por lo demás tiene instituciones y mecanismos propios para su imposición y reproducción, distintos a los que tiene el grupo para reproducir y mantener su identidad propia (políticas e instituciones indigenistas, por ejemplo).

Desde la perspectiva que se postula en este artículo, se deberá distinguir entre la cultura y la identidad propias de un grupo (con sus formas propias de autodenominación), y la construcción de la diferencia que lo ha etnicizado, identificando, incluso, la imposición sobre tal grupo, de una identidad diferente y estigmatizada, como sucede cuando a poblaciones nativas de diferentes países y regiones se les asigna la identidad estigmatizada de ser afros, hispanos 0 asiáticos.

Marcar la diferencia entre lo que son las cualidades culturales de un grupo y los procesos que condujeron a que ese grupo y su cultura fueran clasificados como étnicos (es decir, fueran etnicizados) permitirá dilucidar el empleo que hace la sociedad o grupo dominante de las diferencias culturales para marcar las diferencias (reales o imaginarias), establecer las fronteras y justificar la subordinación y la dominación que ejerce sobre él. Hacer esa distinción permitirá una mejor reflexión sobre lo específico de lo étnico como una cualidad que se atribuye desde el poder al "otro", al dominado, al que se supone y se construye como culturalmente diferente; así, entonces, se podrán esclarecer las especificidades de los procesos de "etnicización", y la articulación de esa forma de dominación con otras, como las de género y las de clase.

Al Identificarse los procesos a través de los cuales un grupo etniciza a otro podría dar lugar, además, a identificarse cuáles son los rasgos culturales que el grupo dominante emplea para justificar las diferencias que lo separan del "otro", así como los mecanismos a través de los cuales lo hace. Dado que estos procesos siempre se desarrollan en condiciones históricas precisas, podrán ser diversos también los elementos culturales empleados para marcar las distancias y las diferencias sociales, así como las características específicas que adopta el dominio al asociarse con otros, como el de clase y el de género. En algunos casos 
serán los fenotipos y las percepciones raciales, en otros la lengua, en otros la religión, en otros las identidades como expresión articulada de la cultura diferente del otro, pero siempre enmarcados por las representaciones sociales que el dominante tiene acerca del dominado 4 . Así, definir lo étnico como un tipo de clasificación que incluye la diferencia y la subordinación cultural como su componente esencial -misma que se articula y contribuye a justificar otros tipos de dominación- puede ayudar, además, a repensar viejos problemas como: a) la presencia de diferentes clases sociales dentro de un grupo considerado étnico; b) los diversos tipos de dominación impuestos a los grupos culturales subordinados, y que no es solo cultural; y c) el uso de las diferencias culturales y de la identidad, para reproducir la subordinación, o para luchar en contra de ella.

\section{Formas de etnicización en México.}

En la Nueva España, la identidad que clasificó a los habitantes prehispánicos conquistados se definió por contraste y oposición a la identidad española y se impuso a las identidades propias y diversas de los pobladores precolombinos que ya habitaban este territorio. El establecimiento de un sistema de dominación sustentado en las diferencias culturales, raciales y religiosas -formalizado mediante las instituciones y las leyes coloniales-, fue la base para construir las relaciones sociales entre indios y españoles que organizaron la totalidad de la vida social ${ }^{5}$. Esa nueva identidad colonial, mediante la cual se nombró y clasificó como indios a una gran diversidad de poblaciones con identidades y culturas propias, es la que en términos contemporáneos puede considerarse como étnica, puesto que fue producto y expresión de un sistema de dominación de tipo étnico, que fue el que caracterizó las relaciones de dominación que se establecieron sobre los distintos pueblos prehispánicos.
Así, de acuerdo a la definición anteriormente dada, podemos afirmar que en México la llamada identidad indígena es una identidad de tipo étnico ya que se produjo, y se impuso, como resultado de las relaciones asimétricas establecidas en los procesos de colonización. En estos procesos, las diferencias culturales, religiosas, raciales y civilizatorias fueron empleadas para construir la diferencia y explicar y justificar el dominio y la explotación de las diversas poblaciones prehispánicas en todos los órdenes de la vida social. Igualmente, fueron etnicizadas las poblaciones negras traídas de África como esclavas y sobre las cuales también se impusieron formas de clasificación, segregación, exclusión y dominación específicas, justificadas a partir de la diferencia construida sobre sus rasgos fenotípicos y culturales.

La identidad étnica como indios, impuesta por el dominio español, en la mayoría de los casos se sobrepuso a las identidades locales producidas a su vez por procesos de interacción específicos entre pobladores diversos. Se generaron así situacionesen las que la identidad como indios se "ponía en acción" en las relaciones de las colectividades locales con la sociedad colonial, mientras que las identidades propias se conservaban y actuaban hacia el interior, tanto como resistencia, como para organizar la vida social. Hubo situaciones, sin embargo, en que las identidades propias se desarticularon y desaparecieron, quedándose entre los pobladores originarios, vigente para la interacción social, únicamente su identidad como indios. Puede suponerse que tal situación se dio sobre todo entre aquéllos que perdieron su adscripción a una colectividad, como sucedió entre los sirvientes, los esclavos y los trabajadores de minas, estancias y haciendas.

En el marco de la construcción del Estado nacional, si bien la igualdad jurídica, social y cultural quedó plasmada como

4 La teoría de las representaciones sociales considera que estas son producidas por el sentido común y que para que existan y que impacten en la vida social no tienen que ser "verdaderas" o "falsas". Es materia de estudio la producción de esas representaciones, su consolidación en los grupos sociales e incluso cómo pueden ser movilizadoras de la acción social (Moscovici, 1989 y J odelet, 1989).

5 Guillermo Bonfil (1972) y Cardoso de Oliveira (1990) señalan el origen colonial de la categoría de indio y destacan su apropiación como categoría política para la movilización y la liberación. 
fundamento legal de la pertenencia y de los derechos ciudadanos de la población, persistió la clasificación étnica de la población culturalmente diferente a la hegemónica (indígena y negra) tanto en ámbitos locales como nacionales. En los primeros, como justificación para mantener relaciones de dominación, segregación y exclusión, y en el nacional por medio del diseño de políticas e instituciones públicas encaminadas a conseguir la integración y la homogeneidad cultural y lingüística, consideradas indispensables para la unidad nacional.

Sobre todo en el caso de las políticas indigenistas desarrolladas para resolver "el problema indígena", estas operaron como organizadoras sociales de las diferencias al reconocer la existencia de un "otro" que debía ser integrado y desarrollado según los patrones de modernidad y civilización que se buscaba para México como país independiente. En el caso de las poblaciones negras, puede suponerse que debido a que su monto era muchísimo menor que el de los indígenas, su futuro se dejó en manos del tiempo y su destino no fue objeto de políticas de Estado especiales. Es decir, quedó sujeto a las dinámicas microregionales y locales en las cuales tenían como opción la extinción o su desaparición mediante el mestizaj $\mathrm{e}^{6}$.

Para el caso mexicano, lo que ha podido verse a lo largo de la historia es que el grupo social culturalmente dominante ha empleado dos formas principales para el establecimiento de las relaciones de dominación étnica:

a) Puede incorporar a losgrupossubordinados en una sola posición de clase -sin respetar sus diferencias de cultura, estratificación y diferenciación social previas- con lo cual los homologa a todos en una sola clase social; o b) Puede imponer su dominación manteniendo la diferenciación social preexistente, la cual es adaptada a su propia estructura de clases, con lo cual ejerce sobre todas las clases y estratos su predominio cultural, el cual le sirve para justificar y reproducir otras formas de dominación, subordinación y explotación.

En este último caso, es posible que existan sectores de los pueblos subordinados que ocupen posiciones de clase alta (dueños de medios de producción, burguesías agrícolas y financieras, etc.) pero que no por ello dejan de padecer la estigmatización, la persecución y la desvalorización de sus identidades y sus culturas propias, ni de trasladar parte de sus bienes y riquezas a los grupos dominantes. Eso sucedió con los nobles indígenas a quienes los españoles permitieron conservar sus privilegios en sus comunidades a cambio de lo cual estos fueran los responsables de controlar a su gente y vigilar que se cumpliera con lo impuesto por las leyes coloniales. $Y$ algo similar ha sucedido en el México contemporáneo en lugares como Chamula, Chiapas, cuando sus élites durante décadas pactaron con el gobierno, en manos del partido en el poder (Partido Revolucionario Institucional, PRI), durante 70 años, para mantener sus privilegios a cambio de la lealtad de toda la comunidad hacia ese partido7. A la primera forma de imponer la dominación se le llamó de dominación étnica estratificada, porque sobre un mismo grupo social coinciden tanto la dominación étnica como la dominación de clase, de modo que a todo el grupo "etnicizado" -pese a las diferencias de clase y estatus que pudo haber tenido antes- se le homogeniza y se coloca dentro una misma clase social subordinada. En él coincide, por tanto, la dominación étnica y la dominación de clase. En este caso, el grupo étnico ocupa una misma posición de clase, es decir, no tiene en su interior miembros con diferente clase social, ya que la posición de clase de todos les ha sido impuesta por el grupo opresor mediante mecanismos, por supuesto, que no solo son culturales, aunque su inclusión en ella se justifique por sus

6 Aguirre Beltrán [1989] dice que la población negra en la Colonia representó solo del 0,1\%al 2,0\% y según él los grupos que hoy se consideran grupos negros (la primera edición de su libro fue en 1958) son producto del mestizaje y la aculturación. Hasta fechas recientes, con el creciente interés por la pluriculturalidad, entre este tipo de población se están dando procesos de recuperación y revaloración cultural.

7 Para el caso de Chamula y sus relaciones con el PRI ver J an Rus (1995). 
Revista CUHSO volumen $13 n \div 1$

rasgos culturales. La conquista, la guerra y el saqueo han sido medios privilegiados para ello, puesto que traen consigo el despojo de territorios, de medios de producción, así como la expropiación o la destrucción de bienes culturales, e incluso el desarraigo de aquellos que son esclavizados. La permanencia de las culturas y de las identidades propias de los grupos dominados están relacionadas, a su vez, con diversas circunstancias: entre otras, de la fuerza de la resistencia o de que existan motivaciones de parte del opresor para permitirlas y fomentarlas. Un ejemplo de cómo todo un grupo fue ubicado en una misma posición social fue el de los negros que fueron traídos a América y esclavizados sin importar que entre ellos hubiera elementos de la nobleza ${ }^{8}$.

El modelo de dominación étnica estratificada ${ }^{9}$ ( $u$ homogeneizante, porque ubica a todos los subordinados étnicamente en una misma clase social) -aunque sin ese nombrees el que normalmente se ha empleado para explicar el caso de los indígenas de México desde la Colonia hasta nuestros días. Esta forma de analizar las cosas, si bien puede ser correcta para ciertos lugares y ha servido para fortalecer las reivindicaciones étnicas, no ha sido muy eficaz para explicar la complejidad y la diversidad de condiciones que vivieron los Ilamados indígenas durante la Colonia, ni tampoco para explicar cómo son ahora, cómo viven, por qué luchan las comunidadesindígenas contemporáneas, ni tampoco para dar cuenta de las particularidades de sus relaciones con las instituciones y la sociedad nacional. En particular, este modelo es ineficiente para explicar las relaciones entre grupo étnico y clases sociales, por lo que ha dado como resultado que se considere de forma mecánica y ahistórica que hay una correspondencia directa entre la posición de la clase y el carácter étnico de un grupo, dejándose sin explicar las ahora visibles diferencias de clase entre la población indígena del país.

La segunda forma de imponer la dominación étnica la he llamado de dominación étnica global (o interclasista, porque mantiene o actualiza la división clasista entre lossubordinados étnicamente), y parece la más adecuada para explicar la diversidad de situaciones que han existido y aún prevalecen en México. Se refiere a situaciones en las que la dominación étnica se impone sobre grupos con formas de organización social estratificadas y clasistas, aunque sobre todas ellas se imponga la diferencia cultural para imponer y reproducir la dominación. En estos casos el grupo dominante mantiene y adecua la diferenciación social que ya existe en su beneficio: permite que sigan persistiendo -para su beneficio- ciertos privilegios de clase entre los dominados, pero impone su dominio sobre todo el conjunto social ${ }^{10}$. Un dominio que no es solo cultural -es económico, jurídico, político y simbólico- pero que se apoya en la diferencia cultural, en la medida que el dominador lo emplea para justificarse ante sí mismo y ante el dominado; así que su predominio se sustenta en la razón histórica que está de su lado, ya que posee las cualidades culturales y civilizatorias que lo ubican en la parte más alta del desarrollo humano. Sus integrantes son los civilizados, los que llevan la verdad de la palabra divina o de la razón científica, los que merecen, en suma, imponer la razón y la verdad sobre el resto del mundo ${ }^{11}$

8 Parsons (1993) señala que Tenochtitlán, en el Período Clásico Tardío, había alcanzado un poder político y económico sin precedentes al convertirse en la cabecera de una confederación de ciudades-Estado (la Triple Alianza) que consolidó su control sobre la cuenca de México. La sociedad estaba compuesta por la nobleza hereditaria (pillis) que incluía a solo un cinco o un diez por ciento de la población, y el pueblo (macehuales); y solo podían ascender socialmente los que destacaban en la guerra o en el comercio a distancia.

9 Las dos formas de establecer la dominación étnica que señalo aquí corresponden a modelos ideales, y son indicativos de las tendencias fundamentales; por ello las tensiones, los conflictos y las decisiones que han conducido en cada momento al predominio de una u otra tendencia deben ser motivo de análisis histórico.

10 Warman (2003: 146-147) señala que desde mediados del siglo XVI la nobleza indígena "fue dividida en dos categorías: los caciques, herederos por sangre de privilegios permanentes, y los principales, que ejercían temporalmente una función de autoridad, funcionarios o burócratas que se agruparon en el cabildo o "república de indios". "Los indios principales, exentos del pago de tributo y de la prestación de trabajo obligatorio, recibieron privilegios especiales como tierras privadas o las mejores de las comunales, trabajadores forzados para labrarlas y sirvientes para sus hogares, bienes de tributo y hasta sueldos cuando se desempeñaban como funcionarios del cabildo".

11 Guy Rozat (2002: 492) analiza cómo los españoles se sentían guiados por Dios en las lejanas tierras de América y cómo la capa discursiva de las crónicas y testimonios del ciclo de la Conquista tuvo por función esencial legitimar los derechos teológicos y naturales de los españoles sobre estas tierras. Así, Sahagún estaba convencido que "a pesar de toda la seducción y de los objetos maravillosos que producía, la cultura indígena que le tocó palpar era fundamentalmente de inspiración diabólica y que por lo tanto debía ser erradicada por completo". 
UNIVERSIDAD CATÓLICA DE TEMUCO

En las situaciones donde la dominación étnica se establece sobre una sociedad con clases, y/o se permite que existan clases sociales al interior del grupo subordinado, la dominación étnica y la dominación de clase adquieren tintes especiales ya que entre los subordinados existen miembros de clases que monopolizan los recursos y el poder dentro de sus comunidades, mientras que frente a la clase similar del grupo opresor, estos son discriminados y estigmatizados por sus características de identidad y cultura. Esas elites de poder viven la tensión entre asumir la cultura y la identidad de los dominantes o mantener sus peculiaridades de identidad y cultura. En muchos casos, su pertenencia, identidad y cultura se vuelven instrumentos de negociación con el grupo dominante para poder afirmar y acentuar sus privilegios de clase, y su propio dominio de clase al interior de su comunidad cultural. En estos casos, su identidad y su cultura se ponen al servicio de su interés por mantener sus privilegios de clase. Un ejemplo de cómo la dominación étnica se ejerce sobre una clase (la burguesía indígena) es el de los indígenas "ricos", como son los comerciantes mazahuas del Estado de México, que pese a su pujante situación económica que los hace ser dueños de millonarios bienes, continúan siendo víctimas de malos tratos y actos vejatorios de sus derechos humanos por parte de los no indígenas -que pueden ser menos ricos que ellos- pero que los discriminan y excluyen por ser indígenas (Pérez Ruiz, 1993).

De la posibilidad de que dentro de un grupo considerado étnico existan diferencias de clase se deriva el hecho de que las reivindicaciones étnicas no siempre puedan resolver los problemas de desigualdad social y económica, que no todas las veces estén al servicio de la equidad y la justicia al interior del grupo, ni se hagan siempre en beneficio de todos los integrantes de las comunidades a nombre de las cuales se promueven. Eso explica por qué, en algunos casos, mientras las elites de poder indígenas emprenden negociaciones con el Estado para defender ámbitos propios de poder, gobierno y justicia, otros miembros de esas comunidades apelan a los derechos universales, al derecho nacional, la ciudadanía o al cambio religioso para oponerse a la tradición cultural bajo la cual las clases dominantes de su propio grupo los explotan y dominan.

Dicho desde otro ángulo, vale reiterar que la condición de subordinación étnica en un grupo no implica homogeneidad ni el igualitarismo en su interior como grupo dominado, ni tampoco, en consecuencia, la existencia interna de relaciones equitativas y democráticas. Por lo cual, un cambio en el Estado nacional para que los indígenas sean reconocidos como integrantes de la nación y estos adquieran derechos propios, no implica necesariamente un cambio estructural en la sociedad nacional para que desaparezcan la desigualdad de clases, la injusticia ni tampoco las otras desigualdades existentes.

\section{BIBLIOGRAFÍA}

ADAMS, RICHARD, 1995. Etnias en evolución social. Estudios de Guatemala y Centroamérica, UAM-I, México.

ANDERSON, BENEDICT, 1997. Comunidades maginadas. Reflexiones sobre el origen y la difusión del nacionalismo, Fondo de Cultura Económica, México.

BABA, HOMI, 1994. The Location of Culture, New Cork-London, Routledge.

BARTH, FREDRIK, 1976. Los grupos étnicos y sus fronteras: la organización social de las diferencias, FCE, México.

BARTOLOMÉ, MIGUEL, 1997. Gente de costumbre y gente de razón. Las identidades étnicas en México, siglo XXI, INI, México.

BONFIL BATALLA, GUILLERMO, 1986. La teoría del control cultural en el estudio de los procesos étnicos, CIESAS, México. 
Revista CUHSO volumen $13 \mathrm{n} \div 1$

BURDIEU, PIERRE, 1980. L'identité et la representation, en Actes de la Recherche en Sciences Sociales, num. 35, París.

CARDOSO DE OLIVEIRA, ROBERTO, 1998. "Etnicidad, eticidad y globalización", en iguel A.Bartolomé y Alicia M. Barabás (Coordinadores), Autonomías étnicas y Estados nacionales, CONACULTA, INAH, México.1992, Etnicidad y estructura social, CIESAS, México. 1990, "La politización de la identidad y el movimiento indígena", en José Alcira(compilador), Indianismo e indigenismo en América, Alianza, México.

COHEN, ABNER. "Ethnicity and Politics", en John Hutchinson y Anthony D. Smith (comp.),Ethnicity, Oxford Universisity Press, Oxford.

DE LA PEÑA, 1999. "Territorio y ciudadanía étnica en la nación globalizada", en Desacatos núm. 1, México.

DEVALLE, SUSANA, 2000. Concepciones de la etnicidad, usos, deformaciones y realidades, en: Leticia Reina (coord.). Los retos de la etnicidad en los estados-nación del siglo XXI, CIESAS-INI-Miguel Ángel Porrúa, México.2002, "Etnicidad e identidad: usos, deformaciones y realidades", en Identidad y etnicidad: continuidad y cambio, El Colegio de México.

DERRIDA, JAQUES, 1989. La escritura y la diferencia, Anthropos, Barcelona.

DÍAZ POLANCO, HÉCTOR, 1995. "Etnia, clase y cuestión nacional", en Héctor Díaz Polanco (compilador) Etnia y nación en América Latina, CONACULTA, México.

FIGUEROA, ALEJ ANDRO, 1994. Por la tierra de los santos. Identidad y persistencia cultural entre yaquis y mayos, CNCA, México.

GEERTZ, CLIFFORD, 1992. La Interpretación de las culturas, Gedisa, Barcelona.

GIBSON-GRAHAM, J.K., "Poststructural Interventions", en Sheppard, E. y Barnes,
T. (editores). A Companion to Economic Geography, Blackwell, Oxford.

GIDDENS, ANTHONY, 1993. Sociología, Alianza, México.

GIMÉNEZ, GILBERTO, 2000. "Identidades étnicas: estado de la cuestión", en Leticia Reyna (coord.) Los retos de la etnicidad en los Estados-Nación del siglo XXI, CIESAS, INI, México, 2003. "Las diferentes formas de discriminación, desde la perspectiva de la lucha por el reconocimiento", Inédito.

GROS, CHRISTIAN, 2000. "Políticas de la etnicidad. Identidad, estado y modernidad, en Leticia Reyna (coord.), Los retos de la etnicidad en los Estados-nación del siglo XXI, CIESAS, INI, México.

GYAN PRAKASH, 1997. "Los estudios de la subalternidad como crítica post-colonial", en Silvia Rivera Cusicanqui (comp.), Debates Post Coloniales. Una introducción a los estudios de la subalternidad, SEPHIS y Aruwiyiri, La Paz. Bolivia, pp. 293- 313.

FOUCAULT, MICHEL, 1992. Microfísica del poder, Ediciones La Piqueta, Madrid.

HALL, STUART Y DU GAY, PAUL, 1996. Questions of Cultural Identity, Sage Publications, Londres.

HOBSBAWM, ERIC, 2000. "La invención de la tradición", en Hobsbawm, Eric y Terance Ranger (editores) La invención de la tradición, Crítica, Barcelona

ISAACS, HAROLD R, 1975. Idols of the Tribe, Group Identity and Political Change, Harper $\&$ Row Oublishers, Nueva York.

J ODELET, DENIS, 1989. Les répresentations sociales, Presses Universitaires de Francia, Paris.

MOSCOVICI, SERGE, 1989. "Des répresentations collectives aux répresentations sociales", en Denis Jodelet (editora), Les répresentations sociales, Presses Universitaires de Francia, 


\section{UNIVERSIDAD CATÓLICA DE TEMUCO}

Paris.

OOMMEN, T.K, 1997. Citizenship, Nationality and Ethnicity, Cambridge, Mass, Polito Press Blackell Publishers.

PÉREZ RUIZ, MAYA LORENA, 2003. "El estudio de las relaciones interétnicas en la antropología Mexicana", en José M. Valenzuela (coord.), Los estudios culturales en México, FCE, México. 2005. ¡Todos somos zapatistas! Alianzas y rupturas entre el EZLN y las organizaciones indígenas de México, INAH, México.

PHILIPPE POUTIGNAT Y J OCELYNE STREIFFFENART, 1995. Théories de l'ethnicité, Paris: Presses Universitaires de France, traducción de Gilberto Giménez, 2005.

SHILLS, EDWARD W., 1957. "Primordial, Personal, Sacre dan Civil Ties", en British J ournal of Sociology, núm. 8, Londres.

RESTREPO, EDUARDO, 2004. Políticas del reconocimiento y alteridad étnica, Universidad de la Ciudad de México, México.

THOMPSON, RICHARD, 1979. "Ethnicity versus Class: An Analysis of Conflict in a North American Chinese Community", Ethnicity, vol. 6, Núm. 4, The National Opinion Reserch at the University of Chicago, Illinois

STAVENHAGEN, RODOLFO, 1992. "La cuestión étnica. Algunos problemas teóricometodológicos", en Estudios Sociológicos Vol. X, Núm. 28, enero-abril, El Colegio de México, México.

VALENZUELA, J OSÉ M., 2000. Decadencia y auge de las identidades, El Colegio de la Frontera Norte y Plaza y Valdés, México.

VARESSE, STEFANO, 2003. "Las diásporas indígenas en Latinoamérica", en José M. Valenzuela, Renacerá la palabra. Identidades y diálogo intercultural", El Colegio de la Frontera Norte, México.

VILAS, CARLOS, 1999. Estado, clase y et ni cidad, Fondo de Cultura Económica, México.
YEROS, PARIS, 1999. "Introduction: On the Uses and Implications of Construcivism", en Paris Yeros (editor), Ethnicity and Nacionalismin Africa. Contructivis Reflections and Contemporany Politics, St. Martin's Press, Nueva York. 